\title{
A ceramic bone substitute containing gentamicin gives good outcome in trochanteric hip fractures treated with dynamic hip screw and in revision of total hip arthroplasty: a case series
}

\author{
Mindaugas Stravinskas ${ }^{1}$, Sarunas Tarasevicius ${ }^{1}$, Simonas Laukaitis ${ }^{1}$, Malin Nilsson ${ }^{2 *}$, Deepak Bushan Raina ${ }^{2}$ and \\ Lars Lidgren ${ }^{2}$
}

\begin{abstract}
Background: The primary objective was to investigate the clinical and radiological outcome in patients undergoing major hip surgery using a novel antibiotic containing bone substitute for local augmentation in trochanteric fracture fixation or revision of total hip arthroplasty (THA).

Methods: We implanted a novel biphasic bone substitute CERAMENT ${ }^{T M} \mid G$ consisting of hydroxyapatite, calcium sulphate and gentamicin for bone regeneration and local antibiotic delivery in 20 patients treated surgically for trochanteric femoral fracture or uncemented hip revision. Preoperative, postoperative, 3 months and 1 year clinical and radiological assessment were performed including registration of any complications. In one trochanteric fracture patient, histological analyses were performed of bone biopsies taken at removal of hardware.
\end{abstract}

Results: None of the trochanteric fractures or revision of THA showed any large migration. No local wound disturbances were seen and no infection was observed at one year follow-up. All trochanteric fractures healed at 3 months with a minimal sliding screw displacement on average $3 \mathrm{~mm}$. Radiological analysis showed signs of bone remodeling and new bone formation in the substitute, illustrated also by histology in the biopsies taken from one trochanteric fracture at one year post-op.

Conclusions: Local CERAMENT ${ }^{\mathrm{TM}} \mid \mathrm{G}$ was shown to be safe in a limited prospective major hip surgery study.

Remodeling of the bone graft substitute was observed in all patients.

Trial registration: EU-CTR2018-004414-18 Retrospectively registered on November 20, 2018.

Keywords: Hip surgery, Infection, Ceramic bone substitute, Antibiotics, Gentamicin, Bone remodeling

\section{Background}

Deep bone and joint infections after orthopaedic procedures are a devastating complication which may require revision surgery and longterm systemic antimicrobial treatment [1]. Conventional approaches used to treat acute infections may not work for chronic biofilm infections and in many cases promote antimicrobial resistance and further biofilm formation [2, 3]. Use of antibiotic-impregnated cement spacers is the standard

\footnotetext{
* Correspondence: malin@lalit.se

${ }^{2}$ Department of Orthopedics, Lund University Hospital, Lund, Sweden Full list of author information is available at the end of the article
}

method to provide direct local delivery of antibiotics which are mainly released from the surface of the cement and limited from the voids within the cement. The most extensively studied and commercially available implant for controlled local release of antibiotics is nonbiodegradable polymethylmethacrylate (PMMA) bone cement [4].

CERAMENT $^{\mathrm{m}} \mid \mathrm{G}$ is an injectable biphasic bone substitute, composed of $60 \%$ calcium sulphate, which resorbs and provides gradual porosity for new bone ingrowth, supported by $40 \%$ hydroxyapatite that acts as matrix for bone cells. It also contains gentamicin

(c) The Author(s). 2018 Open Access This article is distributed under the terms of the Creative Commons Attribution 4.0 International License (http://creativecommons.org/licenses/by/4.0/), which permits unrestricted use, distribution, and reproduction in any medium, provided you give appropriate credit to the original author(s) and the source, provide a link to the Creative Commons license, and indicate if changes were made. The Creative Commons Public Domain Dedication waiver (http://creativecommons.org/publicdomain/zero/1.0/) applies to the data made available in this article, unless otherwise stated. 
sulphate $(175 \mathrm{mg} / 10 \mathrm{~mL})$. Recent studies have shown promising results of CERAMENT ${ }^{\mathrm{Tx}} \mid \mathrm{G}$ on bone regeneration, and prevention or eradication of infection [5]. Dvorzhinskiy et al. described where CERAMENT ${ }^{\mathrm{TM}} \mid \mathrm{G}$ was used for treating osteomyelitis in the tibias of rats [6]. The gentamicin containing bone substitute increased new bone growth as compared with empty control in a debrided osteomyelitic environment. Animals treated with CERAMENT $^{\mathrm{rm}} \mid \mathrm{G}$ showed no evidence of infection and retained a higher bone mass compared to the contralateral (non-operated) side 6 months post-op.

In a previous study, we investigated local elution of gentamicin in patients treated for trochanteric fractures or revision of total hip arthroplasty (THA) when CERAMENT $^{\text {Ts }} \mid G$ was used for bone defect reconstruction [7]. A high level of gentamicin was initially detected in the wound drainage fluid, followed by a decreasing concentration, while in blood serum gentamicin concentration was below the recommended systemic level. However, we found no studies investigating the clinical and radiological outcomes of trochanteric fractures or revision of THA patients, when bone substitute containing antibiotics was used in major hip surgery. This study is a continuation of our previous work [7] and the aim was to investigate the clinical and radiological outcomes of patients undergoing trochanteric fracture fixation or revision of THA with CERAMENT $T^{\mathrm{m}} \mid \mathrm{G}$ used for bone defect augmentation.

\section{Methods}

From June 2014 to September 2016, 20 patients with trochanteric fracture internal fixation surgery using a dynamic hip screw (DHS) and aseptic revision of THA with uncemented stem were included in a single center, prospective, observational study. Patients with systemic aminoglycoside usage before surgery, septic process in the hip joint, psychiatric or neurological disorders, renal failure, impaired hearing, and hypersensitivity to aminoglycosides were excluded.

Synthetic bone graft substitute (CERAMENT ${ }^{\mathrm{mx}} \mid \mathrm{G}$, BONESUPPORT AB, Lund, Sweden) was used to augment the bone defects at implantation of either DHS or after implantation of cementless femoral component. For the fracture patients, CERAMENT ${ }^{\mathrm{tm}} \mid \mathrm{G}$ was injected into the bone defect in the trochanteric region after placing the dynamic screw but before plate implantation (Fig. 1). While in the revision of THA cases CERAMENT ${ }^{\text {TM }} \mid G$ was injected into visible bone defects around the proximal part of the prosthesis after distal fixation of the uncemented stem (Fig. 2). In cases where a cemented acetabular component was chosen, plain PMMA bone cement (without antibiotic) was used for component fixation.

X-ray examination of the operated site was performed the first day after surgery, and patients were mobilized and started to walk using crutches. Clinical and radiological outcome was performed at 3 months and at 1 year follow-up.

For the trochanteric fracture patients radiological analysis included anteroposterior (AP) and lateral views. We estimated postoperative fracture reposition and it was considered satisfactory if femoral neck angle was $<10^{\circ}$ of varus or $<15^{\circ}$ of valgus compared to the uninjured contralateral hip and the fracture displacement was $<5 \mathrm{~mm}$ on both AP and lateral post-operative radiographs [8].

The position of the lag screw was assessed from the mapping of the femoral head and the tip-apex distance (TAD). Fixation was deemed to be adequate if the lag screw was placed to central/central (AP/lateral view), inferior/central, or inferior/posterior Cleveland zones [9]. A TAD of less than $25 \mathrm{~mm}$ was considered optimal. Sliding was measured along the dynamic screw. The

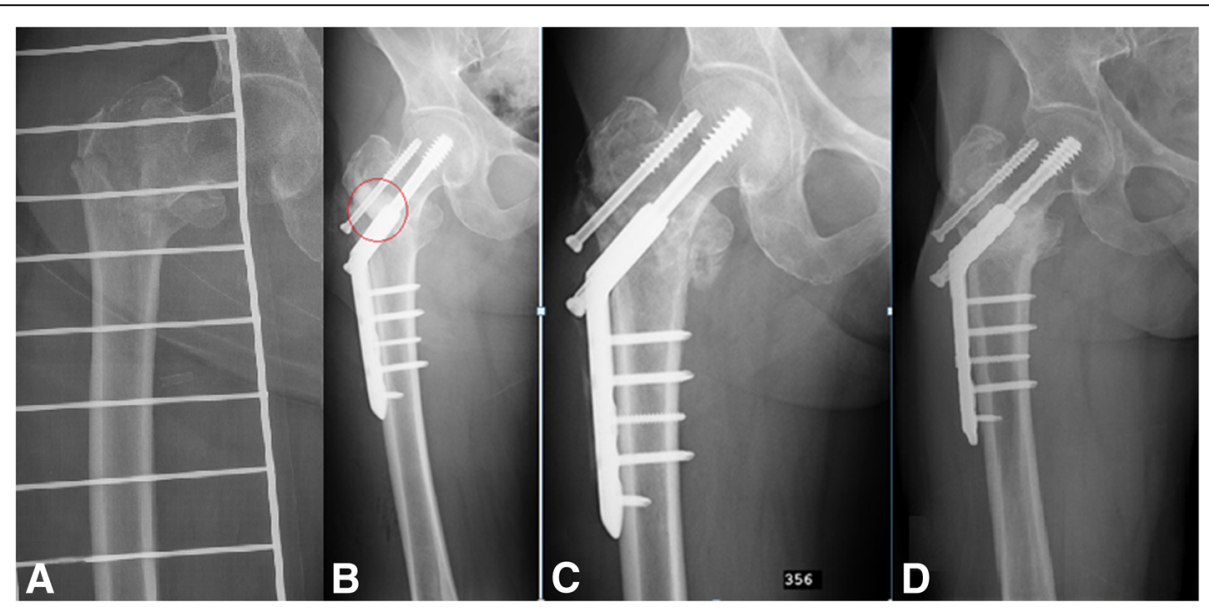

Fig. 1 DHS patient's proximal part of the femur healing. Preoperative image shows the trochanteric fracture (a). In the postoperative image (b) CERAMENT ${ }^{\mathrm{M}} \mid \mathrm{G}$ is seen (circled in red). In the X-ray image after 3 months (c), the bone graft substitute is difficult to differentiate from bone. Image after 1 year $(\mathbf{d})$ shows complete healing. This patient needed DHS removal because of local discomfort 


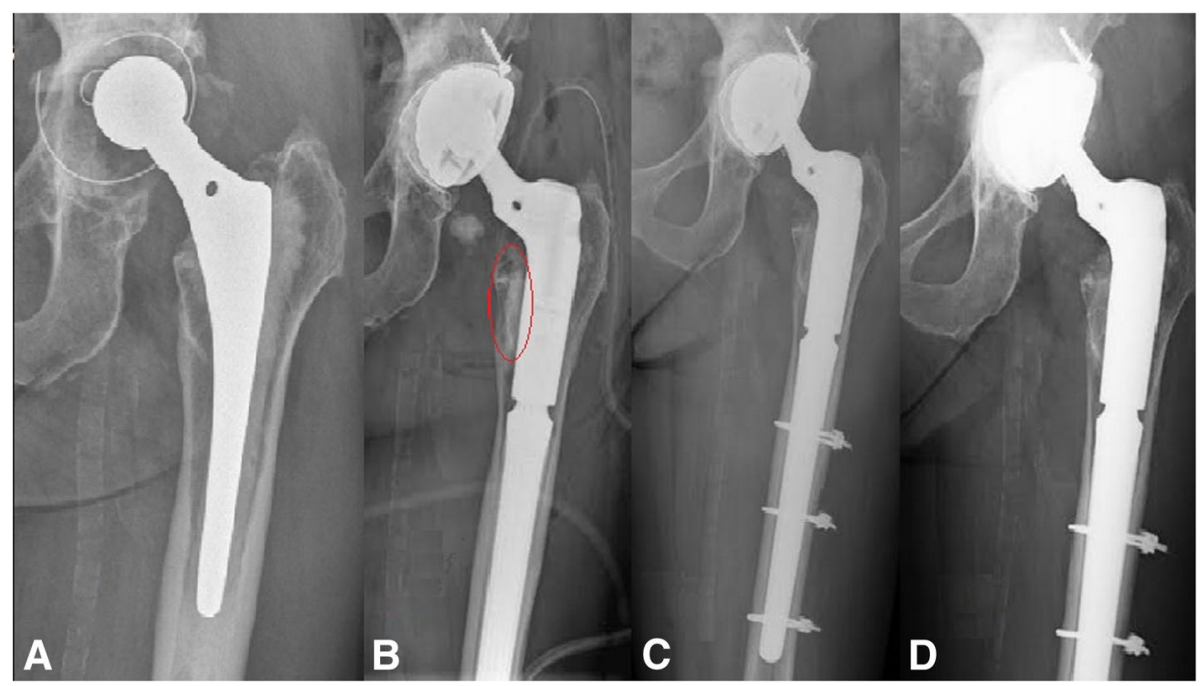

Fig. 2 Revision of THA using a cementless femoral component. Preoperative image shows unstable components (a). The proximal part of the femur postoperatively (b) shows CERAMENT ${ }^{m} \mid G$ present (circled in red). In the X-ray after 3 months (c), the bone graft substitute is difficult to differentiate from bone. Image after 1 year (d) shows bone healing

fracture was considered as healed if bone trabeculae were visible across the fracture line. Absence of bridging bone at the line of the fracture after 3 months was considered as non-union [10].

For revision of THA patients, the radiological analysis was performed of the proximal part of the femur where the CERAMENT ${ }^{\mathrm{mm}} \mid \mathrm{G}$ had been injected. Bone density changes such as: new bone formation, cortical healing as well as subsidence of implant were analyzed.

To evaluate functional outcome at 3 months and 1 year follow-up, patients were asked if they had pain at the operated site and if they were able to bear weight on the operated leg. They were also asked to evaluate their quality of life (QoL) from 1 to 100 using VAS (Visual Analog Scale).

Additionally, all wound or systemic complications related to surgery were recorded.

One patient had hardware removal due to local discomfort of the DHS after 1 year. At the time of the surgery a bone biopsy from the CERAMENT ${ }^{\mathrm{m} m} \mid \mathrm{G}$ implantation site was taken for further histology analysis. The biopsy was fixed in $4 \%$ formalin in neutral buffered saline overnight followed by decalcification in $10 \%$ EDTA solution for 3 weeks. Routine paraffin embedding procedures were used before sectioning the specimen to a thickness of $5 \mu \mathrm{m}$ using a semi-automaticmicrotome (Thermo Scientific, U.S.A). Sections were allowed to adhere to coated glass slides for $48 \mathrm{~h}$ prior to routine H\&E staining.

\section{Results}

The prospective study consisted of 20 patients ( 3 men, 17 women) with a mean age of 74.8 years, $( \pm$ SD 9.5 years, range 57-90 years) who underwent either trochanteric fracture fixation using DHS or aseptic revision of THA using uncemented distal fixation modular stem (10 for each group) (Tables 1 and 2). The distal stem used was tapered and the whole stem coated with Porous Plasma Spray $\left(\mathrm{PPS}^{\circ}\right)$ (Arcos, ZimmerBiomet, USA). A mean of $7.28 \mathrm{~mL}( \pm$ SD $1.10 \mathrm{~mL}$, range $5-9 \mathrm{~mL})$ of CERAMENT ${ }^{\mathrm{mx}} \mid \mathrm{G}$ was implanted for patients with trochanteric hip fracture and mean of $7.61 \mathrm{~mL}( \pm \mathrm{SD} 0.49 \mathrm{~mL}$, range $7-9 \mathrm{~mL})$ for revision of THA patients.

Out of 20 included patients, one trochanteric fracture patient died during follow-up unrelated to the implantation of CERAMENT ${ }^{\mathrm{Tm}} \mid \mathrm{G}$ (myocardial infarction), and one refused follow-up, leaving 8 trochanteric fracture and 10 revision of THA patients for final analysis.

Radiological analysis of trochanteric fractures showed that reposition of bone fragments was satisfactory according to previously described criteria in all cases. AP view evaluation revealed that the dynamic screw was placed in the center of the femoral head for 9 patients while for one patient it was placed inferiorly, while in lateral view all dynamic screws were placed centrally. Mean TAD value was $19.7 \mathrm{~mm}( \pm \mathrm{SD} 3.3 \mathrm{~mm}$, range 14.3-25.2 mm) (Table 3).

Table shows the type of the fracture according to the AO classification, the placement of the lag screw in femoral head, tip-apex distance (TAD), caput-collum-diaphyseal (CCD) angles and femoral neck shortening after 3 months and 1 year follow-up.

The mean sliding distance of the screw (shortening of the femoral neck) was $3.1 \mathrm{~mm}( \pm$ SD $3.5 \mathrm{~mm}$, range $0.7-11.8 \mathrm{~mm}$ ) after 3 months and remained almost unchanged at 1 year follow-up (Table 3). Caput-collum- 
Table 1 Trochanteric fracture patient data

\begin{tabular}{lllllllll}
\hline Patient No. & Age & Gender & Pain in op leg & Clin function & VAS for QoL 3 months & VAS for QoL 1 year & Outcome & Complications \\
\hline 1 & 83 & F & No & Full & 85 & 90 & Healed fr. & - \\
2 & 83 & F & No & Can't walk & $30^{\text {a }}$ & No foll up & No foll up & - \\
3 & 62 & F & No & Full & 65 & 88 & Healed fr. & - \\
4 & 75 & F & No & Full & 70 & 80 & Healed fr. & - \\
5 & 85 & F & Died & - & - & - & - & - \\
8 & 64 & F & No & Difficult & 80 & 80 & Healed fr. & - \\
14 & 81 & F & No & Full & 60 & 80 & Healed fr. & - \\
15 & 80 & F & No & Full & 80 & 90 & Healed fr. & - \\
19 & 78 & F & No & Full & 80 & 80 & Healed fr. & - \\
20 & 89 & F & No & Full & 50 & 90 & Healed fr. & - \\
Mean & 78.0 & & & & 71.3 & 4.8 & \\
S.D. & 8.3 & & & 11.4 & & \\
\hline
\end{tabular}

a excluded from Mean and S.D. due to no follow-up at 1 year

diaphyseal (CCD) angles of the operated hips were in the range of $120^{\circ}-134^{\circ}$ (mean $129.9^{\circ} \pm \mathrm{SD} 3.7^{\circ}$ ), and similar to the CDD angles of the healthy contralateral hip (mean $129.1^{\circ} \pm \mathrm{SD} 2.5^{\circ}$ ) (Table 3), with no varus or valgus deformity after fracture fixation. Radiological bone healing was observed in all available trochanteric fracture patients for follow-up.

At 3 months follow-up, 7 patients were walking independently, with no need of walking aids, while one patient had some walking problems and used a cane for support. The same results were observed at 1 year follow-up (Table 1).

Radiological visualision of CERAMENT ${ }^{\mathrm{mm}} \mid \mathrm{G}$ was possible on postoperative $\mathrm{x}$-rays, however at 3 months and 1 year follow-up the material was difficult to differ from new bone growing into the apatite scaffold (Fig. 1).
One trochanteric fracture patient (No 3) had additional surgery after 1 year follow-up, the hardware was removed due to some discomfort in trochanteric region (Fig. 1). During the surgery, the extraction of the dynamic screw was extremely difficult, probably due to excessive bone ongrowth on the hardware. Bone biopsies were taken from the trochanteric region for subsequent analysis. Histological analysis showed viable and mature bone in all biopsies (Fig. 3). High magnification of one of the specimens showed the presence of a loose hydroxyapatite conglomerate (indicated by the black arrows in Fig. 4). A second specimen showed islands of viable trabecular bone and the space between the trabeculae was filled with marrow like tissue (Fig. 5).

All 10 revision of THA patients reported having full recovery at 3 months, which was unchanged at 1 year follow-up. Two complained of light pain in the

Table 2 Cementless hip revision patient data

\begin{tabular}{|c|c|c|c|c|c|c|c|c|c|c|}
\hline \multirow{2}{*}{$\begin{array}{l}\text { Patient } \\
\text { No. }\end{array}$} & \multirow[t]{2}{*}{ Age } & \multirow[t]{2}{*}{ Gender } & \multirow{2}{*}{$\begin{array}{l}\text { Pain in } \\
\text { op leg }\end{array}$} & \multirow{2}{*}{$\begin{array}{l}\text { Leg } \\
\text { function }\end{array}$} & \multirow{2}{*}{$\begin{array}{l}\text { VAS of QoL } \\
\text { at } 3 \text { months }\end{array}$} & \multirow{2}{*}{$\begin{array}{l}\text { VAS of QoL } \\
\text { at } 1 \text { year }\end{array}$} & \multicolumn{2}{|c|}{ Defect type (Paprovsky classification) } & \multirow{2}{*}{$\begin{array}{l}\text { Graft } \\
\text { healing }\end{array}$} & \multirow[t]{2}{*}{ Complications } \\
\hline & & & & & & & acetabulum & femur & & \\
\hline 6 & 67 & $\mathrm{~F}$ & No & Full & 60 & 75 & $1 \mathrm{lb}$ & IIla & yes & - \\
\hline 7 & 62 & $\mathrm{~F}$ & No & Full & 75 & 80 & $\| \mathrm{a}$ & Illb & yes & - \\
\hline 9 & 67 & M & No & Full & 70 & 70 & Ila & $111 \mathrm{~b}$ & yes & - \\
\hline 10 & 90 & M & No & Full & 90 & 100 & IIla & Illa & yes & - \\
\hline 11 & 84 & $\mathrm{~F}$ & Yes & Full & 60 & 85 & Illa & IIIb & yes & - \\
\hline 12 & 57 & M & No & Full & 40 & 78 & $11 \mathrm{~b}$ & IIla & yes & - \\
\hline 13 & 68 & $\mathrm{~F}$ & No & Full & 65 & 80 & IIla & $\|$ & yes & - \\
\hline 16 & 68 & $\mathrm{~F}$ & No & Full & 85 & 95 & $11 \mathrm{~b}$ & $\|$ & yes & - \\
\hline 17 & 74 & $\mathrm{~F}$ & Yes & Full & 50 & 65 & Ila & Illa & yes & - \\
\hline 18 & 78 & $\mathrm{~F}$ & No & Full & 70 & 90 & Illa & IIla & yes & - \\
\hline Mean & 71.5 & & & & 66.5 & 81.8 & & & & \\
\hline S.D. & 9.6 & & & & 14.3 & 10.4 & & & & \\
\hline
\end{tabular}


Table 3 Data of the trochanteric fractures - screw placement, angles and neck shortening

\begin{tabular}{|c|c|c|c|c|c|c|c|c|c|}
\hline $\begin{array}{l}\text { Patient } \\
\text { No. }\end{array}$ & $\begin{array}{l}\text { Fracture } \\
\text { type }\end{array}$ & $\begin{array}{l}\text { Screw } \\
\text { position }\end{array}$ & $\begin{array}{l}\text { TAD } \\
(\mathrm{mm})\end{array}$ & $\begin{array}{l}\text { CCD angle } \\
\text { after op. }\left({ }^{\circ}\right)\end{array}$ & $\begin{array}{l}\text { CCD angle } \\
\text { healthy leg }\left({ }^{\circ}\right)\end{array}$ & $\begin{array}{l}\text { CCD angle } \\
\text { at } 3 \text { months }\left({ }^{\circ}\right)\end{array}$ & $\begin{array}{l}C C D \text { angle } \\
1 \text { year }\left(^{\circ}\right)\end{array}$ & $\begin{array}{l}\text { Neck shortening } \\
\text { at } 3 \text { months ( } \mathrm{mm} \text { ) }\end{array}$ & $\begin{array}{l}\text { Total shortening } \\
\text { at } 1 \text { year }(\mathrm{mm})\end{array}$ \\
\hline 1 & A3.1 & Central/Central & 25.2 & 131 & 134 & 130 & 128 & 11.8 & 13.4 \\
\hline 2 & A 1.2 & Central/Inferior & 14.3 & 133 & 130 & - & - & - & - \\
\hline 3 & A2.1 & Central/ Central & 22.2 & 130 & 128 & 127 & 127 & 4.7 & 6.5 \\
\hline 4 & A 1.2 & Central/ Central & 17.8 & 129 & 130 & 129 & 128 & 2.4 & 2.7 \\
\hline 5 & A2.1 & Central/ Central & 16.2 & 120 & 130 & died & - & - & - \\
\hline 8 & A 1.2 & Central/ Central & 19.7 & 134 & 131 & 133 & 133 & 2.0 & 2.2 \\
\hline 14 & A2.1 & Central/ Central & 17.6 & 132 & 127 & 128 & 128 & 0.7 & 1.1 \\
\hline 15 & A 1.1 & Central/ Central & 18.6 & 129 & 130 & 126 & 126 & 0.8 & 0.9 \\
\hline 19 & A 1.3 & Central/ Central & 20.3 & 132 & 126 & 130 & 130 & 1.0 & 1.2 \\
\hline 20 & A 1.1 & Central/ Central & 24.6 & 129 & 125 & 129 & - & 1.2 & \\
\hline Mean & & & 19.7 & 129.9 & 129.1 & 129.0 & 128.6 & 3.1 & 4.0 \\
\hline S.D. & & & 3.3 & 3.7 & 2.5 & 2.0 & 2.1 & 3.5 & 4.2 \\
\hline
\end{tabular}

operated hip (Table 2) but radiological analysis showed that the bone density had increased in the proximal part of the femurs, where the bone defect was filled with CERAMENT ${ }^{\mathrm{m}} \mid \mathrm{G}$. No bone resorption was observed. No signs of osteolysis or loosening were observed in the acetabular or femoral components (Table 2).

Mean value of VAS for quality of life for the hip revision patients after 3 months was $66.5( \pm$ SD 14.3, range $40-90)$ and at 1 year $81.8( \pm$ SD 10.4, range $65-100)$, while for DHS patients the mean value was $71.3( \pm$ SD 11.4, range $50-80)$ at 3 months and $84.8( \pm$ SD 4.8 , range $80-90)$ at 1 year follow-up (Tables 1 and 2).

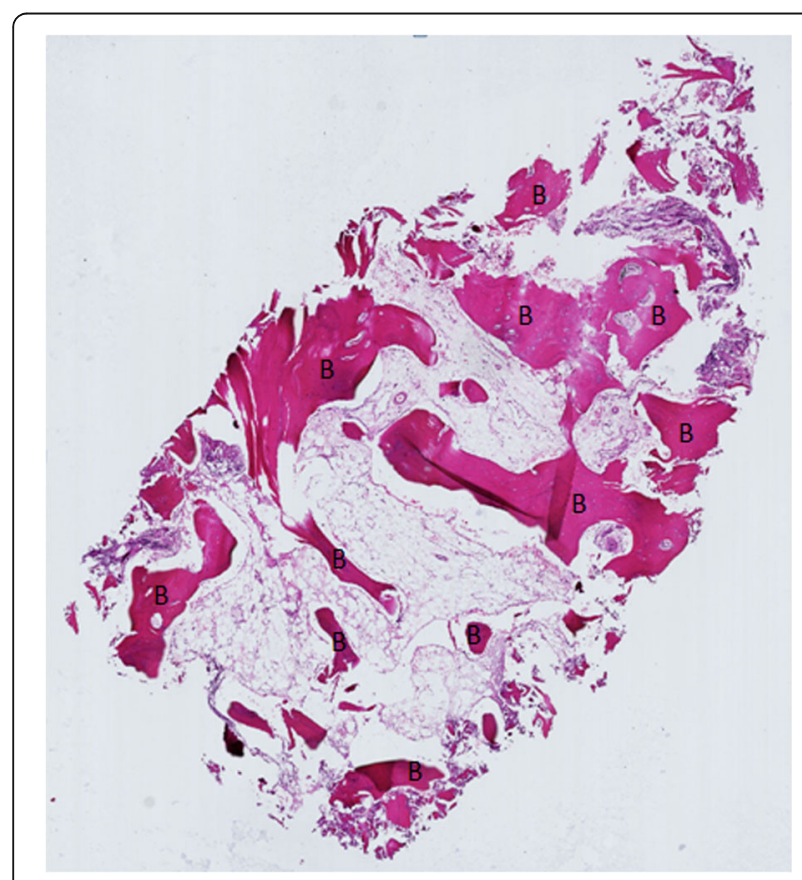

Fig. 3 Specimen of the tissue surrounding the removed lag screw shows viable and mature bone (B)
None of the patients had impaired hearing, kidney function or any allergic reactions to gentamicin. No wound complications or local infections were registered in any patient.

\section{Discussion}

To our knowledge, this is the first study investigating the local use of biodegradable bone graft substitute with antibiotics for bone defect reconstructions in aseptic revision of THA and trochanteric fracture patients.

A previous study showed that gentamicin from CERAMENT $^{\mathrm{mx}} \mid \mathrm{G}$ elutes with a high burst rate through the first days after operation [7]. The local level of the concentration is sufficient not only to prevent infection, but also for eradication of recurrent bone

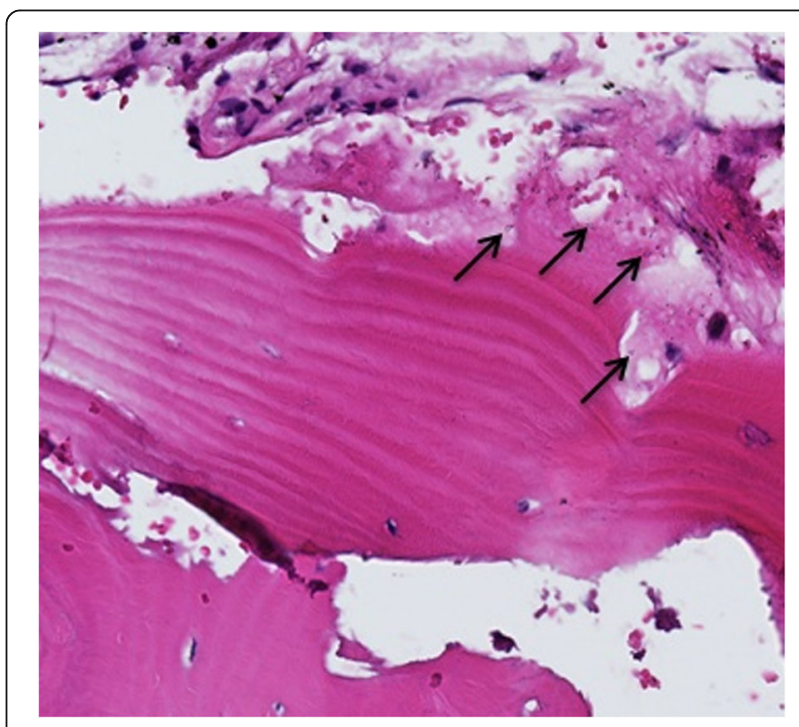

Fig. 4 Higher magnification shows the presence of hydroxyapatite conglomerate (indicated by the black arrows) 


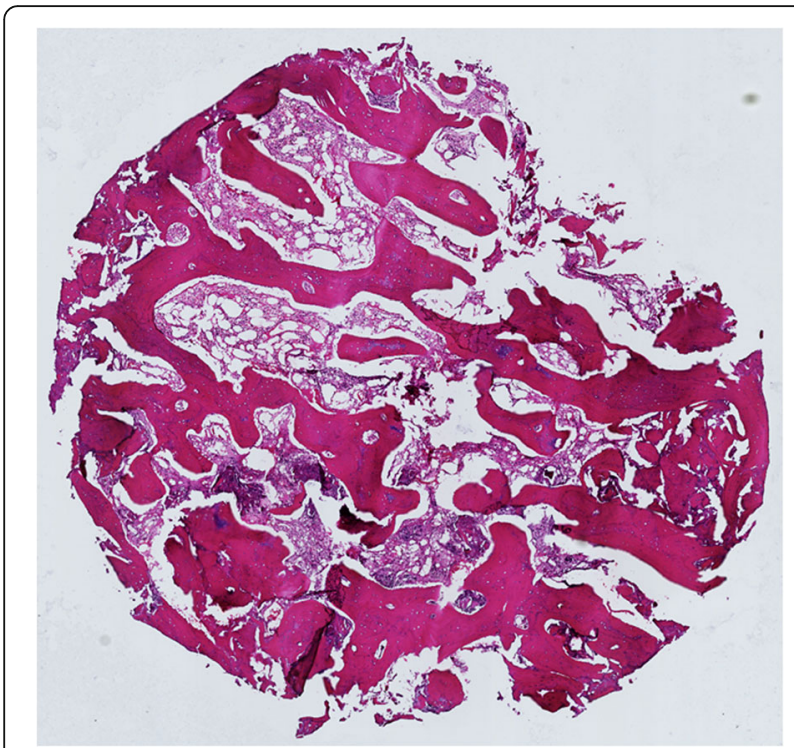

Fig. 5 A second biopsy of the tissue surrounding the removed lag screw. Islands of viable trabecular bone is seen and the space between trabeculae is filled with marrow-like tissue

or joint infections [11], thus is it not surprising that no signs of infection were observed in our investigated group.

The bone graft substitute does not improve immediate prosthesis-bone interface strength. In short term the use of a proximal bone graft substitute might not be necessary as a distally fixed stem would provide sufficient support. However, after remodeling, the proximal bone graft substitute gives mechanical support due to increased new bone formation around the prosthesis. The antibiotic elusion provided from the bone graft substitute protects the bone bed from infections. This is in concordance with findings reported in previously performed in vivo studies, where an uncemented knee joint prostheses and CERAMENT ${ }^{\mathrm{Tm}} \mid \mathrm{G}$ were implanted in rabbits and showing better implant fixation in the host bone as compared to the control group without CERAMENT ${ }^{\mathrm{sm}} \mid \mathrm{G}$ [5]. Our experience of removing a dynamic hip screw from the trochanteric region where CERAMENT ${ }^{\mathrm{Tm}} \mid \mathrm{G}$ had been implanted was that extremely high forces were needed. We assume that excessive new bone formation, probably related to CERAMENT ${ }^{\mathrm{sm}} \mid \mathrm{G}$ implantation and subsequent ongrowth into the sliding screw may explain the difficulties in hardware removal. However, no conclusions can be drawn from this limited case series and additional comparative studies need to be carried out. Histology confirmed new bone formation growth into the ceramic material.

Radiological analysis of the trochanteric fracture patients after DHS implantation showed a low level of dynamic screw migration, with an avarage of $3 \mathrm{~mm}$ at 3 months in our group with osteoprotic geriatric patients, while in a larger study by Platzer et al. a mean value of screw migration together with femoral neck shortening in non geriatric patients was reported to be $11 \mathrm{~mm}$ at 1 year follow-up [12]. Augmentation with a slow resorbing calcium phosphate (apatite) has not been shown to improve fixation in femoral neck fractures [10]. Since long term fixation is dependent on the amount and quality of new bone formed around the implant, we believe that the use of a biphasic material with part being replaced by ingrowing bone that surrounds the apatite may be beneficial for fracture stability and implant fixation. By adding antibiotics to the bone graft substitute, it is in addition possible to prevent surgical site infections in surgery carrying high risk [11]. The disadvantage of using antibiotics as standard in ceramic material may lead to over-use and not be necessary for all patients and even be harmful for patients suffering from renal insufficiency [13]. We suggest that CERAMENT ${ }^{\mathrm{Tm}} \mid \mathrm{G}$ implantation at the fracture site could improve healing, bone formation and stabilization in the trochanteric fractures, thus preventing dynamic screw migration and shortening of the femoral neck.

There are several limitations in this study. The number of patients included is low and the study should be considered as a clinical feasibility study to show for the first time clinical outcome of an antibiotic eluting injectable bone substitute CERAMENT ${ }^{\mathrm{mm}} \mid \mathrm{G}$ used in major hip surgery. The prime objective was to extensively analyze the pharmacokinetics which has been reported elsewhere [7], but it contained no clinical follow-up. The study reports trochanteric fractures and revision THA, which are different conditions and with different outcome. The methods for clinical follow-up could have used in addition to VAS other patient related outcome instruments.

\section{Conclusions}

Our limited study indicates that local CERAMENT ${ }^{\mathrm{Tm}} \mid \mathrm{G}$ could be safely used in revision of THA and trochanteric fractures, to prevent infection and fill bone defects. No local or systemic complications were found and circulation disturbances in the femoral head were not seen.

\begin{abstract}
Abbreviations
AP: Anteroposterior; CCD: Caput-collum-diaphyseal; DHS: Dynamic hip screw; EDTA: Ethylenediaminetetraacetic acid; H\&E: Haematoxylin and eosin stain; PMMA: Polymethylmethacrylate; PPS ${ }^{*}$ Porous Plasma Spray; QoL: Quality of Life; TAD: Tip-apex distance; THA: Total hip arthroplasty; VAS: Visual Analog Scale
\end{abstract}

\section{Acknowledgements}

The materials were provided by BONESUPPORT AB, Lund, Sweden.

\section{Funding}

The financial support to the researchers was granted by VINNOVA innovation agency in Sweden (grant 2017-00269), VR-Research funding agency in Sweden (grant 2015-06717) and the Foundation for Disabled people. The funding bodies had no role in the design of the study, data collection, analysis, and interpretation of data or in writing the manuscript. 


\section{Availability of data and materials}

The datasets supporting the conclusions of this article are included within the article.

\section{Authors' contributions}

MS: Collected patient data and performed the surgeries, wrote Background, Methods and Results, read and approved the manuscript. ST: Supervised the collection of data and the surgeries and wrote Discussion and Conclusion, read and approved the manuscript. SL: did the biopsy for the histology study, read and approved the manuscript. MN: did statistics analyses and read and approved the manuscript. DBR: prepared the bone taken at revision and performed the histology and interpretation, gave valuable comments during writing as well as reviewed and approved the manuscript. LL: supervised and managed the collaboration between the two institutes, read and approved the manuscript.

\section{Ethics approval and consent to participate}

The study was approved by the local ethical committee at Lithuanian University of Health, Kaunas, Lithuania (No. BE-2-43) and written informed consent to participate in the study was obtained from all participants.

\section{Consent for publication}

Written consent for publication was obtained from all participants as a paragraph included in the informed consent.

\section{Competing interests}

Prof Lars Lidgren is a member of the board of BONESUPPORT AB and Orthocell Ltd.

\section{Publisher's Note}

Springer Nature remains neutral with regard to jurisdictional claims in published maps and institutional affiliations.

\section{Author details}

${ }^{1}$ Lithuanian University of Health, Kaunas, Lithuania. ${ }^{2}$ Department of Orthopedics, Lund University Hospital, Lund, Sweden.

Received: 17 October 2017 Accepted: 22 November 2018

Published online: 06 December 2018

\section{References}

1. Koh CK, Zeng I, Ravi S, Zhu M, Vince KG, Young SW. Periprosthetic joint infection is the main cause of failure for modern knee arthroplasty: an analysis of 11,134 knees. Clin Orthop Relat Res. 2017:475:2194-201.

2. Gilbert P, Das J, Foley I. Biofilm susceptibility to antimicrobials. Adv Dent Res. 1997:11:160-7.

3. Rafiq I, Gambhir AK, Wroblewski BM, Kay PR. The microbiology of infected hip arthroplasty. Int Orthop. 2006;30:532-5.

4. Cancienne JM, Tyrrell Burrus M, Weiss DB, Yarboro SR. Applications of local antibiotics in orthopedic trauma. Orthop Clin North Am. 2015:46:495-510.

5. Zampelis $V$, Tägil M, Lidgren L, Isaksson H, Atroshil I, Wang J-S. The effect of a biphasic injectable bone substitute on the interface strength in a rabbit knee prosthesis model. J Orthop Surg Res. 2013. https://doi.org/10.1186/ 1749-799X-8-25.

6. Dvorzhinskiy A, Perino G, Chojnowski R, Van Der Meulen M, Ross F, Bostrom $M$, Yang N. Cerament bone void filler with gentamicin increases bone formation and decreases detectable infection in a rat model of debrided osteomyelitis. Bone Joint J. 2015;97B:9.

7. Stravinskas M, Horstmann P, Ferguson J, Hettwer W, Nilsson M, Tarasevicius S, Petersen MM, McNally MA, Lidgren L. Pharmacokinetics of gentamicin eluted from a regenerating bone graft substitute. Bone Joint Res. 2016;5:427-35.

8. Baumgaertner MR, Solberg BD. Awareness of tip-apex distance reduces failure of fixation of trochanteric fractures of the hip. J Bone Joint Surg Br. 1997;79:969-71.

9. Zirngibl B, Biber R, Bail HS. How to prevent cut-out and cut-through in biaxial proximal femoral nails: is there anything beyond lag screw positioning and tip-apex distance. Int Orthop. 2013;37:1363-8.

10. Mattsson P, Larsson S. Calcium phosphate cement for augmentation did not improve results after internal fixation of displaced femoral neck fractures: a randomized study of 118 patients. Acta Orthop. 2006;7:251-6.
11. McNally MA, Ferguson JY, Lau CK, Diefenbeck MD, Scarborough M, Ramsden AJ, Atkins BL. Single-stage treatment of chronic osteomyelitis with a new absorbable, gentamicin-loaded, calcium sulphate / hydroxyapatite biocomposite. A prospective series of 100 cases. Bone Joint J. 2016;98-B:1289-96.

12. Platzer $P$, Thalhammer $G$, Wozasek GE, Vécsei V. Femoral shortening after surgical treatment of trochanteric fractures in nongeriatric patients. J Trauma. 2008;64:982-9.

13. Nergelius G, Vinge E, Grubb A, Lidgren L. Renal impairment after hip or knee arthroplasty. Urinary excretion of protein markers studied in 59 patients. Acta Orthop Scand. 1997;68(1):34-40.

\section{Ready to submit your research? Choose BMC and benefit from:}

- fast, convenient online submission

- thorough peer review by experienced researchers in your field

- rapid publication on acceptance

- support for research data, including large and complex data types

- gold Open Access which fosters wider collaboration and increased citations

- maximum visibility for your research: over $100 \mathrm{M}$ website views per year

At BMC, research is always in progress.

Learn more biomedcentral.com/submissions 